\title{
Study of Bacterial Isolates in Community Acquired Pneumonia
}

\author{
Sarah Firdous* and S. Jaya Prakash Rao \\ Affiliated to Osmania general hospital, Hyderabad, India \\ *Corresponding author
}

\section{A B S T R A C T}

\section{Keywords}

Pneumonia, Infection, Sputum culture, Klebsiella

Article Info

Accepted: 07 December 2018 Available Online: 10 January 2019
Community Acquired Pneumonia (CAP) is an infection of pulmonary parenchyma. Despite availability of potent antibiotics, CAP remains a common and serious illness with significant morbidity and mortality. Objective of the study is to identify the bacteria causing community acquired pneumonia and risk factors associated with it. 100 clinically diagnosed CAP patients attending medical out-patient and admitted in Upgraded Osmania General Hospital selected. Study was conducted during Sept 2016 to Oct 2017. Sputum samples were cultured and organism identified by standard biochemical tests. Out of 100 included, 52 had identifiable etiology. Most frequent organism was Klebsiella pneumoniae $(\mathrm{n}=27)$ followed by Staphylococcus aureus $(\mathrm{n}=14)$. People in the age group of 45-65 years were more susceptible. Major risk factor was smoking.

\section{Introduction}

Community Acquired Pneumonia (CAP) is a commonly encountered lower respiratory tract infection by clinicians. It is defined as, "an infection of the pulmonary parenchyma. Infectious Diseases Society of America defines Community Acquired pneumonia (CAP) as "an acute infection of the pulmonary parenchyma that is associated with at least some symptoms of acute infection (cough, dyspnoea, fever) accompanied by the presence of an acute infiltrate on a chest radiograph or auscultatory findings (ronchi, crepitations) consistent with pneumonia in a patient not hospitalized or residing in a long-term care facility for more than 14 days before onset of symptoms". CAP is usually acquired via inhalation or aspiration of pulmonary pathogenic organisms into a lung segment or lobe. Less commonly, from secondary bacteraemia from a distant source or by contiguous extension from infected pleural or mediastinal space. Pneumonia may present as acute (community acquired or nosocomial), sub-acute or chronic. CAP commonly affects people of all ages, with higher incidence occurring in very young to very old age groups.

In the United State, pneumonia is the sixth leading cause of death with annual incidence of CAP ranging from 4 to 5 million cases. But the problem is much greater in developing 
countries, though definite statistics are lacking, pneumonia remains a leading cause of death in India according to study by Bansal $\mathrm{S}$ (2004). Pneumonia is increasingly common in patients with co-morbidity like chronic obstructive pulmonary disease (COPD), Diabetes mellitus (DM), renal failure, Congestive heart failure (CHD) and Bronchiectasis. The cause of CAP is often difficult to establish. Despite the progress made in the clinical diagnosis of pneumonia, it takes a few days to identify the causative microorganism and the aetiology of half of all patients with CAP remains uncertain as per study conducted by Ishida T (1998). The bacteriological profile of CAP is not the same across various countries. It also varies within the same country with time, due to differences in the frequency of use of antibiotics, environmental pollution, awareness of the disease and life expectancy. Clinicians need reliable data on the prevalence of different etiological agent in their area of residence.

The present study has been conducted in Upgraded Department of Microbiology, Osmania General Hospital, Hyderabad, Telangana, with the objective to know the prevalence of etiological microorganism of CAP and risk factors associated with it.

\section{Materials and Methods}

This study was undertaken in a 750 bedded multi-specialty referral hospital in Hyderabad catering to both urban and semi-urban populations. This prospective study was carried out after taking clearance from ethical committee, in the Department Of Microbiology, Osmania general hospital, Hyderabad, Telangana.

\section{Source of data}

Patients attending Osmania General Hospital above 15 years of age clinically diagnosed as
CAP were selected from Medicine Department. The study conducted during a time period of 1 year from September 2016 to October 2017.

\section{Sample size}

100 patients of CAP attending medical outpatient department and admitted in Upgraded Osmania General Hospital, Hyderabad were included in the study after taking informed consent

\section{Inclusion criteria}

All patients over $15 y$ rs attending medical outpatient department or admitted with at least two of the following symptoms.

\section{Fever}

Cough

Production of purulent sputum

Breathing difficulty

Chest pain

Leucocytosis (WBC > 10,000/cumm)

New infiltrate in chest radiograph

Patients not on antibiotic therapy.

\section{Exclusion criteria}

Patients already on antibiotic therapy Patients not willing to give informed consent Patients with Pulmonary infarction, pulmonary edema, interstitial lung disease.

Patients receiving immunosuppressive therapy.

HIV patients

\section{Sample collection}

Sputum (deeply coughed) from the patients is collected in sterile wide mouthed leaked proof container. In patients who could not expectorate sputum spontaneously, sputum induction was done using 3\% hyper-tonic saline nebulization. Label the sample 
appropriately and transport it to laboratory immediately.

The following data were recorded on enrolling: age, gender, comorbidities, antimicrobial treatment prior to enrolment, duration of symptoms before the diagnosis of pneumonia, clinical symptoms (body temperature, pleuritic chest pain, purulent sputum), haematology (total WBC with differential counts, platelet count, hemoglobin), chest radiographic pattern, and smoking and alcohol consumption.

\section{Sputum processing:}

\section{Macroscopic appearance}

Nature of the sputum was observed-purulent, muco-purulent, mucoid, or blood stained.

\section{Microscopic examination}

\section{Gram's stain}

Bartlett's grading system was used for assessing the quality of sputum samples.

\section{Culture}

Sputum was inoculated onto 5\% sheep Blood agar, Chocolate agar and Mac Conkey agar.

Plates were incubated for $18-24$ hours at $37^{\circ} \mathrm{c}$ in candle jar.

The organisms isolated were identified by standard biochemical reactions.

\section{Results and Discussion}

112 patients with age $>15$ years of age, attending medical out-patient or admitted in Osmania General Hospital, Hyderabad, between September 2016 and October 2017 were included in the study. After sputum microscopy, 12 were excluded from the study because, 7 sputum samples did not satisfy Barlett scoring criteria and 5 were positive for Candida species. From the 100 which were included in the study, 71 were males and 29 were females (Fig. 1 and 2).

This study was conducted to find out the bacterial etiology in patients with Community acquired pneumonia and sensitivity profile, as it is one of the leading causes of the morbidity and mortality in the world as per study conducted by Bansal (2004). Aetiological agents vary from area to area, so do their antibiotic susceptibility profile.

In the present study, $52 \%$ of bacterial isolates were recovered from 100 sputum samples which were included in the study. A similar percentage of was reported by Madhulata et al., (2013) whereas $71.6 \%$ positivity of culture was shown by Ramana et al., (2013) from Andhra Pradesh

Males were found to be more commonly affected with a $\mathrm{M}$ : $\mathrm{F}$ ratio of 2.4:1 which correlated to a study by Madhulata et al., (2013) who also found males were commonly affected, with the $\mathrm{M}$ : $\mathrm{F}$ ratio being 2.7:1. A study by Wattanathum et al., (2003) showed Male to female ratio 1.6:1, Basheer shah et al., (2010) and Rohinikumar et al., (2015) found male to female ratio of 1.3 and 1.7:1 respectively.

In our study, age of patients ranged from $15-$ 93 yrs. The most affected age group was 4565 yrs, which correlated with study by Reechaipichitkel Wipa et al., (2002) who found the mean age was 56.9 years.

Smoking is well known and important risk factor for community acquired pneumonia through alteration in mechanisms of host defense system. It causes changes in mucociliary clearance, bacterial adherence and respiratory epithelium. Tobacco smoking is most important risk factor for development of 
COPD and it is recognized as risk factor for other respiratory infections. In the present study, most common identified risk factor was smoking $55 \%$ followed by Alcohol consumption in $30 \%$, Diabetes Mellitus in $20 \%$ and COPD in $11 \%$. Study conducted by Bansal et al., (2004) showed 71\%, Shah Bashir Ahmed et al., (2010) found smoking as a predisposing factor in $65 \%$ followed by COPD in 57\% and Madhulata (2013) reported smoking as risk factor in $45 \%$ followed by COPD in 26\% and Diabetes in 8\%. In contrast
Oberoi (2006) found 26.6\% and Rohinikumar (2015) found smoking as risk factor in $37 \%$ cases (Fig. 4).

Maximum number of patients presented with cough, fever, sputum production, pleuritic chest pain, and dyspnea, this correlated with previous studies (Fig. 3). Sputum culture was positive in $52 \%$. Similar observations were reported by Madhulata et al., (2013) and Chawla et al., (2008) (Table 1-9).

Table.1 Age and Sex wise distribution of cases $(n=100)$

\begin{tabular}{|c|c|c|c|}
\hline Age & No. of cases & Males & Females \\
\hline $\mathbf{1 5 - 2 5}$ & 8 & 5 & 3 \\
\hline $\mathbf{2 6 - 3 5}$ & 13 & 8 & 5 \\
\hline $\mathbf{3 6 - 4 5}$ & 12 & 8 & 4 \\
\hline $\mathbf{4 6 - 5 5}$ & 13 & 8 & 5 \\
\hline $\mathbf{5 6 - 6 6}$ & 26 & 19 & 7 \\
\hline $\mathbf{6 6 - 7 5}$ & 21 & 19 & 2 \\
\hline $\mathbf{7 6 - 8 5}$ & 5 & 3 & 2 \\
\hline $\mathbf{8 6 - 9 5}$ & 2 & 1 & 1 \\
\hline Total & 100 & 71 & 29 \\
\hline
\end{tabular}

Table.2 Common symptoms observed in the study group

\begin{tabular}{|c|c|c|}
\hline Symptom & No. of cases & Percentage (\%) \\
\hline Cough with expectoration & 98 & $98 \%$ \\
\hline Fever & 92 & $92 \%$ \\
\hline Chest pain & 57 & $57 \%$ \\
\hline Dyspnea & 60 & $60 \%$ \\
\hline
\end{tabular}

Table.3 Associated risk factors noted in the study group

\begin{tabular}{|c|c|c|}
\hline Risk factor & No. of cases & Percentage \% \\
\hline Smoking & 55 & $55 \%$ \\
\hline Alcohol & 30 & $30 \%$ \\
\hline Diabetes mellitus & 20 & $20 \%$ \\
\hline COPD & 11 & $11 \%$ \\
\hline Asthma & 3 & $3 \%$ \\
\hline Heart disease & 3 & $3 \%$ \\
\hline
\end{tabular}


Table. 4 Culture positives in sputum $(n=100)$

\begin{tabular}{|c|c|c|}
\hline Sputum culture & No. of samples & Percentage \% \\
\hline Positive & 52 & $52 \%$ \\
\hline Negative & 48 & $48 \%$ \\
\hline
\end{tabular}

Table.5 Total no. of isolates in sputum culture $n=52$

\begin{tabular}{|c|c|c|}
\hline Isolates & No. & Percentage \% \\
\hline Klebsiellapneumoniae & 27 & 51.9 \\
\hline Staphylococcus aureus & 14 & 26.9 \\
\hline Escherichia coli & 4 & 7.6 \\
\hline Pseudomonasaeroginosa & 3 & 5.7 \\
\hline Streptococcus pneumoniae & 3 & 5.7 \\
\hline Streptococcus pyogenes & 1 & 1.9 \\
\hline Total & 52 & 100 \\
\hline
\end{tabular}

Table.6 Distribution of isolates according to age

\begin{tabular}{|c|c|c|c|c|c|c|c|c|}
\hline Age & $\begin{array}{c}\text { No } \\
\text { Pts }\end{array}$ & K.pneumoniae & $\begin{array}{c}\text { Staph } \\
\text { aureus }\end{array}$ & E.coli & $\begin{array}{c}\text { Pseudo } \\
\text { Monas }\end{array}$ & $\begin{array}{c}\text { S. } \\
\text { pneumonia }\end{array}$ & $\begin{array}{c}\text { S. } \\
\text { pyogenes }\end{array}$ & $\begin{array}{c}\text { Total } \\
\text { isolates }\end{array}$ \\
\hline $\mathbf{1 5 - 2 5}$ & 8 & 3 & - & - & - & - & - & 3 \\
\hline $\mathbf{2 6 - 3 5}$ & 13 & 2 & 1 & 1 & - & - & - & 4 \\
\hline $\mathbf{3 6 - 4 5}$ & 12 & 3 & 1 & 1 & - & - & - & 5 \\
\hline $\mathbf{4 6 - 5 5}$ & 13 & 2 & 2 & - & 1 & 1 & - & 6 \\
\hline $\mathbf{5 6 - 6 5}$ & 26 & 8 & 5 & 1 & 1 & 1 & 1 & 17 \\
\hline $\mathbf{6 6 - 7 5}$ & 21 & 8 & 2 & 1 & 1 & - & - & 12 \\
\hline $\mathbf{7 6 - 8 5}$ & 5 & - & 3 & - & - & 1 & - & 4 \\
\hline $\mathbf{8 6 - 9 5}$ & 2 & 1 & - & - & - & - & - & 1 \\
\hline Total & 100 & 27 & 14 & 4 & 3 & 3 & 1 & 52 \\
\hline
\end{tabular}

Table.7 Studies showing the most common affected sex

\begin{tabular}{|c|c|c|c|}
\hline Author & Year & Most common in & M:F ratio \\
\hline WattanathumA et al., & 2003 & Males & $1.6: 1$ \\
\hline Basheer shah et al., & 2010 & Males & $1.3: 1$ \\
\hline Madhulata CK et al., & 2013 & Males & $2.7: 1$ \\
\hline Rohinikumar et al., & 2015 & Males & $1.7: 1$ \\
\hline Present study & 2017 & Males & $2.4: 1$ \\
\hline
\end{tabular}


Table.8 Occurrence of Clinical symptoms in various studies

\begin{tabular}{|c|c|c|c|c|c|}
\hline Author & Year & Fever (\%) & $\begin{array}{c}\text { Cough + expectoration } \\
(\mathbf{\%})\end{array}$ & $\begin{array}{c}\text { Chest pain } \\
(\boldsymbol{\%})\end{array}$ & Dyspnoea (\%) \\
\hline Irfan M et al., & 2009 & 77.5 & 72 & 23 & 46 \\
\hline Shah BA et al., & 2010 & 95 & 99 & 75 & - \\
\hline $\begin{array}{c}\text { Madhulata CK } \\
\text { et al., }\end{array}$ & 2013 & 75 & 99 & 37 & 45 \\
\hline $\begin{array}{c}\text { Rohinikumar } \text { et } \\
\text { al., }\end{array}$ & 2015 & 91 & 81 & 30 & 44 \\
\hline Present study & 2017 & 92 & 98 & 57 & 60 \\
\hline
\end{tabular}

Table.9 Sputum culture positivity in various studies

\begin{tabular}{|c|c|c|c|c|c|}
\hline Author & Place & Year & $\begin{array}{c}\text { Culture positive } \\
\%\end{array}$ & $\begin{array}{c}\text { K. pneumoniae } \\
\text { isolates }(\%)\end{array}$ & $\begin{array}{c}\text { S. aureus } \\
\text { isolates }(\%)\end{array}$ \\
\hline Madhulata et al., & India & 2013 & 54.5 & 44.7 & 2.6 \\
\hline Mythri et al., & India & 2013 & 52.7 & 55.2 & 2.6 \\
\hline Priyanka Paul & India & 2013 & 66.4 & 33.3 & 17.7 \\
\hline $\begin{array}{c}\text { TripathiPurti et } \\
\text { al., }\end{array}$ & India & 2014 & 42 & 42 & 20.3 \\
\hline $\begin{array}{c}\text { Rohini Kumar et } \\
\text { al., }\end{array}$ & India & 2015 & 46 & 19.5 & - \\
\hline Sunil Vijay & India & 2016 & 77 & 36.7 & 22.2 \\
\hline Present study & India & 2017 & 52 & 51.9 & 26.9 \\
\hline
\end{tabular}

Fig.1\&2

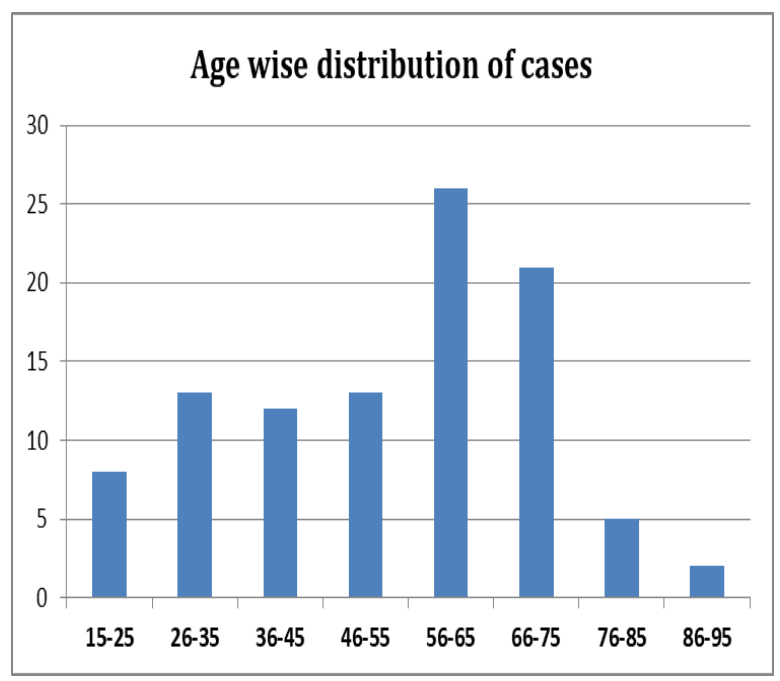

Sex wise distribution of cases

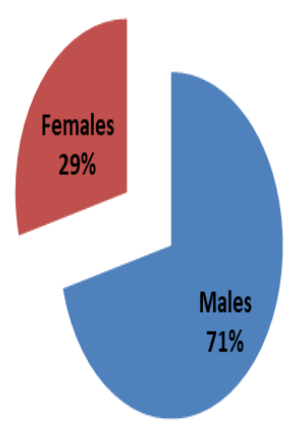


Fig.3

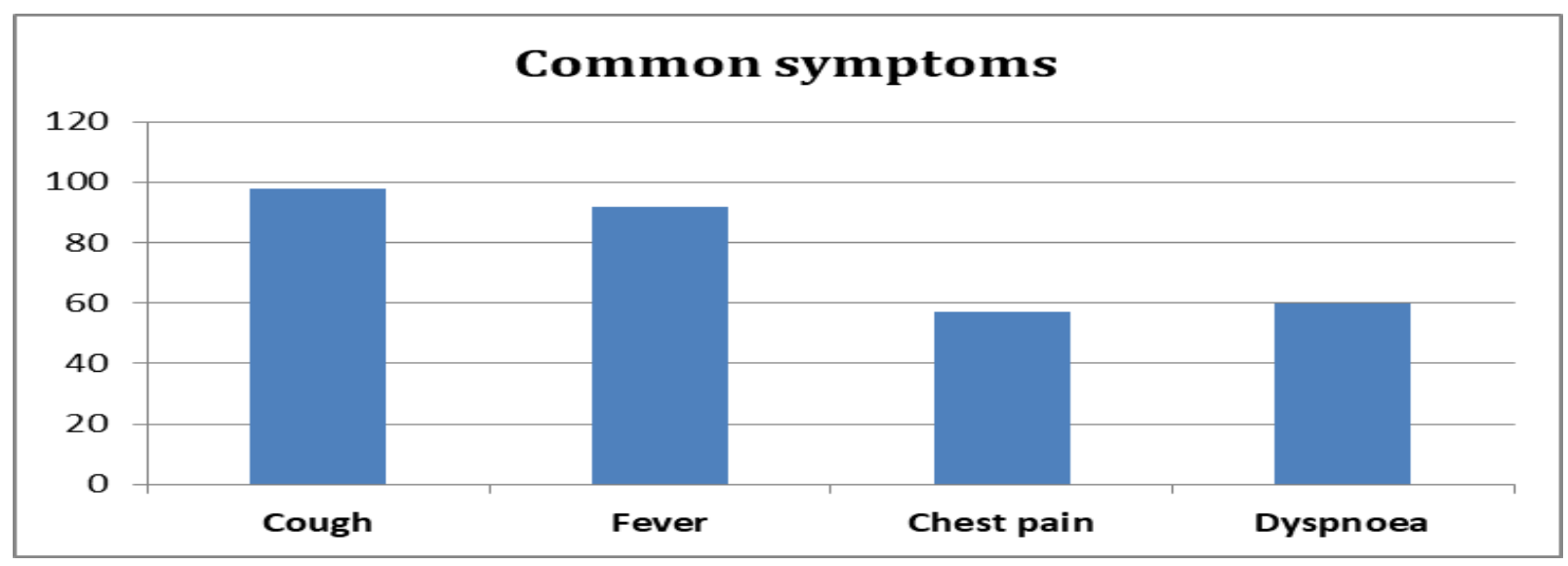

Fig.4 Associated Risk factors noted in the study

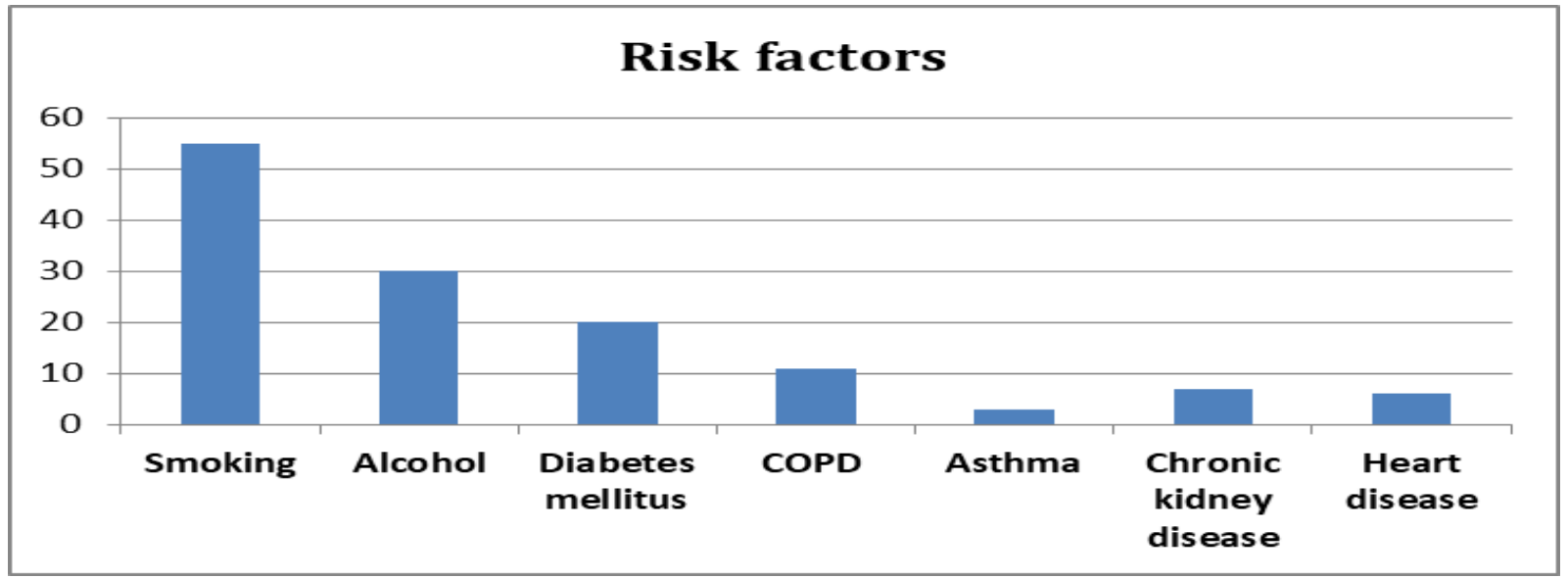

Fig.5 Culture positives in sputum

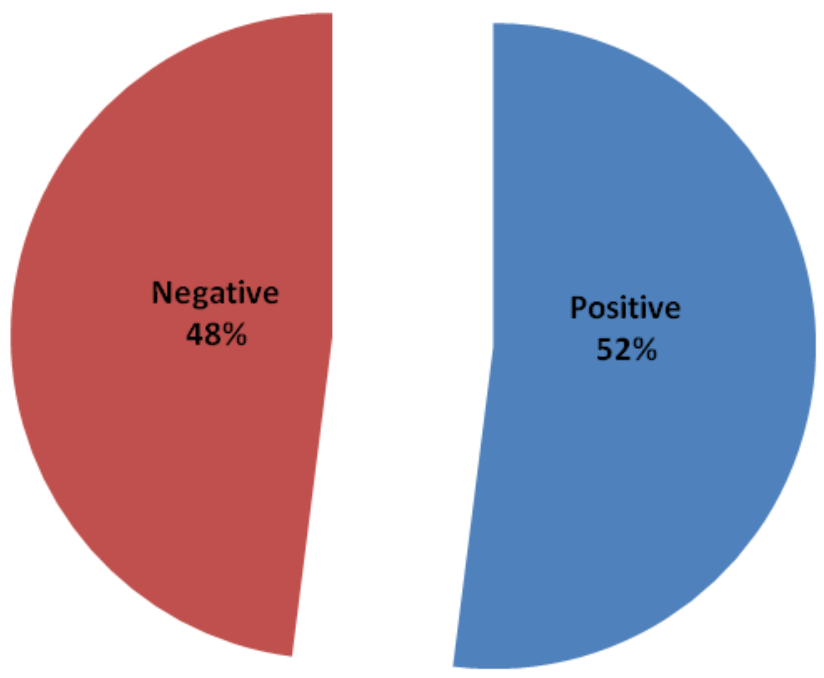


Fig.6 Total no of isolates in sputum culture

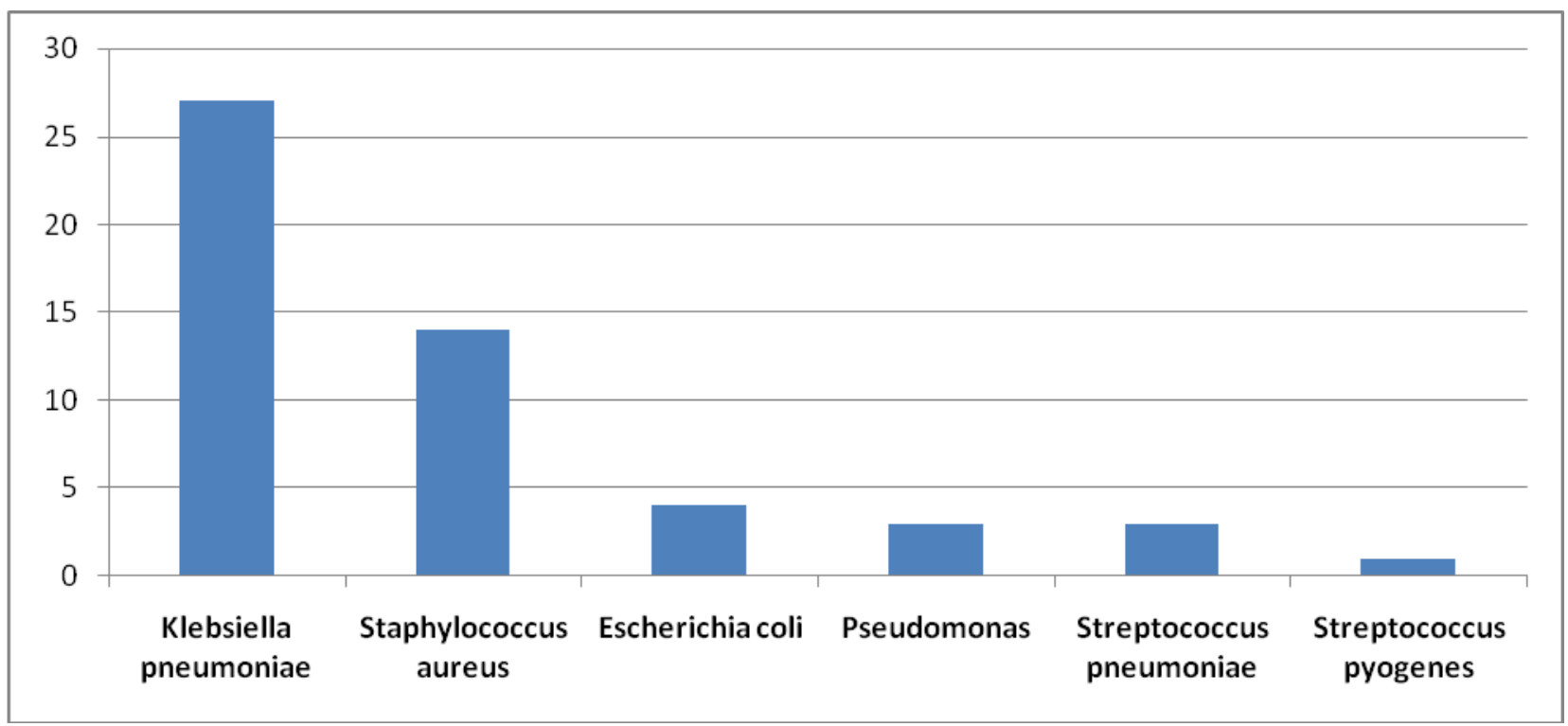

Fig.7 Distribution of isolates according to age

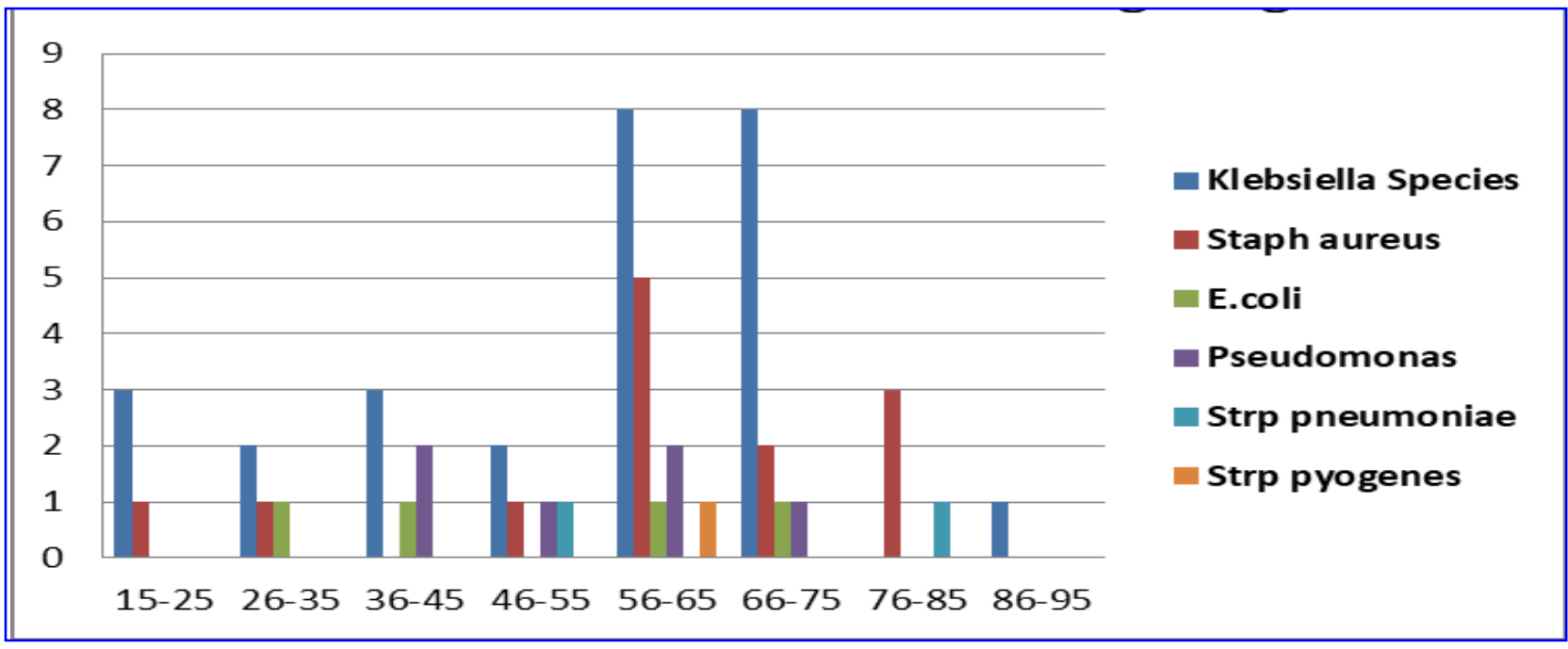

In the present study, sputum culture positivity was $52 \%$ and Klebsiella pneumoniae was most common pathogen isolated which correlated with Mythri et al., High isolation of $77 \%$ culture positivity was reported by Sunil Vijay (2016) Staphylococcus aureus was second most common organism isolated in the present study which correlates with Sunil Vijay et al., (2016). Whereas only $2.6 \%$ of Staphylococcus aureus was reported by
Madhulata et al., (2013) and Mythri et al. (2013).

In the present study aetiology remained unknown in $48 \%$ cases, which correlates with previous study, according to which, even with use of extensive laboratory testing and various invasive procedures etiological confirmation could be achieved in $45-70 \%$ according to studies conducted by Arabinca et 
al., (2002) and Ewing S et al., (2002). Though Streptococcus pneumoniae have been reported as the commonest organisms causing community acquired pneumonia, Indian studies over the last three decades have reported higher incidence of Gram negative organisms among culture positive pneumonia as per study conducted by Brown JS (2009). Increased incidence of Klebsiella pneumoniae may reflect the effects of different environmental conditions on transmission and host factors such as abnormal nutritional status, comorbidities or genetic background (Fig. 5, 6 and 7).

In the present study Klebsiella pneumoniae was the major pathogen. Majority (60\%) of patients was above 45 years of age and habituated to smoking, or had COPD. Old age, smoking and underlying respiratory diseases such as COPD impair pulmonary defences and predispose to CAP caused by gram negative bacteria. Our hospital being a tertiary referral hospital, we receive community acquired pneumonia patients with wide range of severity, many of them carrying multiple co morbidities. These patients might have been exposed to antibiotics for treatment of respiratory or non-respiratory tract infections.

\section{Summary}

Males constitute a major proportion of patients affected by CA-Pneumonia.

People in the age group of 45-65 years were more affected by CAP.

The common risk factor observed was Smoking followed by Alcoholism and Diabetes mellitus.

Sputum culture was positive in 52\% of patients.
Klebsiella pneumoniae (51.9\%) was the most common organism isolated. Other Gram negative bacteria isolated were Escherichia coli $(7.6 \%)$ and Pseudomonas aeruginosa $(5.7 \%)$.

Among Gram positive cocci isolated, Staphylococcus aureus (26.9\%) was the most common organism followed by Streptococcus pneumoniae (5.7\%) and Streptococcus pyogenes $(1.9 \%)$.

In conclusion, the present study was undertaken to know the prevalence of etiological microorganism of CAP and their antimicrobial susceptibility pattern, so that specific treatment can be advocated. Out of the 100 patients included in the study, 71 were males and 29 were females. Positive sputum culture was obtained in 52\% and the major pathogen isolated was Klebsiella pneumoniae (51.9\%) followed by Staphylococcus aureus (26.9\%).

\section{References}

Arancibia F, Bauer TT, Ewing S, Mensa J, Gonzalez J, Michael S et al., Community acquired pneumonia due to gram negative bacteria and Pseudomonas aeruginosa. Arch internmed. 2002 Sep; 162(16):18471858.

Bansal S, Kashyap S, Pal LS, Goel S. Clinical and bacteriological profle of community-acquired pneumonia in Shimla, Himachal Pradesh. Ind $\mathbf{J}$ Chest Dis Allied Sci2004; 46: 17-22

Brown JS. Geography and the aetiology of community acquired pneumonia. Respirology. 2009 Nov; 14 (8):10681071.

Chawla. K, Mukhopadhyay C, Majumdar M, Bairy. Bacteriological profile and their antibiogram of acute exacerbations of chronic obstructive pulmonary 
diseases in hospital based studies. J ClinDiagn Research. 2008; 2(1):612616.

Dr. BOMA GIRIRAJ., et al., Journal of Biomedical and Pharmaceutical Research 4(4): 2015, 65-68

Dr. Rohini Kumar Patel, Dr. D Prashanta Kumar, Dr. Bichitrananda Roul, Study of Bateriological and Clinical Profile in Community Acquired Pneumonia, International $\mathbf{J}$ of Advanced Research 2015; 3(9): 1042-1056.

DrMythri.S, DrNataraju H.V, Bacteriological profile of community Acquired Pneumonia, IOSR-JDMS, volume 12, issue 2(Nov-Dec, 2013), PP16-19

Ewing S, Torres A, Angeles Marcos M, Angrill J, Rano, de Roux A, et al., Factors associated with unknown etiology in patients with community acquired pneumonia. Eur. Respir J. 2002 Nov; 20(5): 1254-1262.

Fauci AS, Braunwald E, Kasper DL, Hauser SL, Longo DL, Jameson JL, et al., editors. Harrison's principles of internal medicine. 17th ed. New York: McGraw Hill; 2008.

Ishida T, Hashimoto T, Arita M, Ito I, Osawa M. Etiology of community acquired pneumonia in hospitalized patients: A 3-year prospective study in Japan. Chest 1998; 114: 1588-93.

K V Ramana, Anand Kalaskar, Mohan Rao, Sanjeev D Rao. Aetiology and Antimicrobial Susceptibility Patterns of Lower Respiratory Tract Infections (LRTI's) in a Rural Tertiary Care Teaching Hospital at Karimnagar, South India. American Journal of Infectious Diseases and Microbiology. 2013; 1(5):101-105. doi: 10.12691/ajidm-1-5-5.

Kumar, Abbas, Fausto and Mitchell, Robbins text book of Basic Pathology, $8^{\text {th }}$ edition South-Asia edition Elsevier chapter 13, page no's 509-21.
MacFarlance J. Community acquired pneumonia. $\mathrm{Br} J$ Dis Chest 1987;81:116-27.

Madhulata CK, Pratibha Malini J, Ravikumar Kl, Rashmi KJ. Bacterial Profile and Antibiotic Sensitivity Pattern of microorganisms from Community acquired Pneuonia RJPBCS. 2013 July-Sep; 4(3):1005-1011.

Muhammad Irfan, Syed FayyazHussain, Khubaib Mapara, Shafia Memon et al., Mortality in a Tertiary care Hospitalized patients. J Pak Med Asso July 2009; Vol. 59' No.7: 448-52

Oberoi Aroma, Agarwal A. Bacteriological profile, serology and antibiotic sensitivity pattern of microorganisms from community acquired pneumonia. JK science. 2006 Apr-Jun; 8 (2):7982.

Priyanka Paul Biswas, Tukaram Prabhu K. Bacterial causes of Lower Respiratory Tract Infections In Patients Attending Central Referral Hospital, Gangtok with Reference to Antibiotic Resistance Pattern. Journal of Evolution of Medical and Dental Sciences 2013; Vol. 2, Issue 42, October 21; Page: 8126-8135.

Reechaipichitkul W, Tantiwong P. Clinical features of community acquired pneumonia treated at sringarind hospital Khoenkaen Thailand. Southeast Asian J Trop Med Public Health. 2002 Jun; 33(2): 355-361.

Shah BA, Singh, Naik MA, et al., Bacteriological and clinical profile of Community acquired pneumonia in hospitalized Patients Lung India 2010; 27: 54-57.

Sunil Vijay, Gaurav Dalela, Prevalence of LRTI in patients Presenting with productive cough and their antibiotic resistanc pattern, $\mathrm{J}$ of clinical and Diagnostic Research Jan 2016; 10(1): 9-12. 
TripathiPurti C, Dhote Kiran. Lower Respiratory Tract Infections: Current Etiological Trends and Antibiogram. J Pharm Biomed Sci., 2014; 04(03): 249-255.

Wattanathum A, Chaoprasong C, Nunthapisud P, Chantaratchada S,
Limpairojnn, N., Jatakanon, A., et al., community acquired pneumonia in South East Asia: the microbial differences between ambulatory and hospitalized patients. Chest 2003 May; 123(5): 1512-1519.

\section{How to cite this article:}

Sarah Firdous and S. Jaya Prakash Rao. 2019. Study of Bacterial Isolates in Community Acquired Pneumonia. Int.J.Curr.Microbiol.App.Sci. 8(01): 644-654.

doi: https://doi.org/10.20546/ijcmas.2019.801.072 